\title{
Low-pressure support vs automatic tube compensation during spontaneous breathing trial for weaning
}

\author{
Claude Guérin ${ }^{1,2,3,4^{*}}$ (B), Nicolas Terzi ${ }^{5,6,7}$, Mehdi Mezidi ${ }^{2,8}$, Loredana Baboi ${ }^{8}$, Nader Chebib²,8 ${ }^{2}$ Hodane Yonis ${ }^{8}$, \\ Laurent Argaud ${ }^{1,2}$, Leo Heunks ${ }^{9}$ and Bruno Louis L $^{3,4}$
}

\begin{abstract}
Background: During spontaneous breathing trial, low-pressure support is thought to compensate for endotracheal tube resistance, but it actually should provide overassistance. Automatic tube compensation is an option available in the ventilator to compensate for flow-resistance of endotracheal tube. Its effects on patient effort have been poorly investigated. We aimed to compare the effects of low-pressure support and automatic tube compensation during spontaneous breathing trial on breathing power and lung ventilation distribution.

Results: We performed a randomized crossover study in 20 patients ready to wean. Each patient received both methods for 30 min separated by baseline ventilation: pressure support $0 \mathrm{cmH}_{2} \mathrm{O}$ and automatic tube compensation $100 \%$ in one period and pressure support $7 \mathrm{cmH}_{2} \mathrm{O}$ without automatic tube compensation in the other period, a $4 \mathrm{CmH}_{2} \mathrm{O}$ positive end-expiratory pressure being applied in each. Same ventilator brand (Evita XL, Draeger, Germany) was used. Breathing power was assessed from Campbell diagram with esophageal pressure, airway pressure, flow and volume recorded by a data logger. Lung ventilation distribution was assessed by using electrical impedance tomography (Pulmovista, Draeger, Germany). During the last 2 min of low-pressure support and automatic compensation period breathing power and lung ventilation distribution were measured on each breath. Breathing power generated by the patient's respiratory muscles was $7.2(4.4-9.6)$ and $9.7(5.7-21.9) \mathrm{J} / \mathrm{min}$ in low-pressure support and automatic tube compensation periods, respectively $(P=0.011)$. Lung ventilation distribution was not different between the two methods.
\end{abstract}

Conclusions: We found that ATC was associated with higher breathing power than low PS during SBT without altering the distribution of lung ventilation.

Keywords: Work of breathing, Respiration, Artificial, Respiratory muscles, Mechanical ventilator weaning, Positivepressure ventilation

\section{Background}

Weaning intensive care unit (ICU) patients from invasive mechanical ventilation relies on a daily screening for eligibility, and if present, a spontaneous breathing trial (SBT) testing patient capacity to breathe without respiratory assistance [1]. SBT can be done by either setting a low-pressure support ventilation (PS) level or

\footnotetext{
*Correspondence: claude.guerin@chu-lyon.fr

${ }^{1}$ Médecine-Intensive Réanimation, Hopital Edouard Herriot, $\mathrm{CHU}$ de Lyon, Lyon, France

Full list of author information is available at the end of the article
}

allowing the patient to breathe spontaneously through the endotracheal tube without any support from the ventilator (T-piece). Even though both SBT methods are almost equivalent to predict weaning outcome [2] [3], American guidelines suggested performing the first weaning trial using PS rather than T-piece to hasten extubation [4]. Recent data are consistent with this recommendation [5].

Low PS level was thought as a mean to compensate for the endotracheal tube airflow resistance $\left(R_{\mathrm{ET}}\right)$ [6]. However, the fact that low PS actually reduced work of 
breathing (WOB) as compared to T-piece [7] questioned this concept. The WOB after extubation, which was similar as that during SBT $[8,9]$, was better predicted with T-piece than with low PS [10]. A meta-analysis of studies comparing at least two SBT techniques found that low PS reduced WOB by $30 \%$ as compared to T-piece [10]. Therefore, low PS should provide a further respiratory assistance beyond $R_{\mathrm{ET}}$ compensation. We reasoned that the only way to provide a support that would just compensate for $R_{\mathrm{ET}}$ is the automatic tube compensation (ATC) option available in many ICU ventilators [11]. ATC works as a closed-loop during insufflation (and/or exsufflation) to compensate for the non-linear pressureflow relationship across endotracheal tube or tracheostomy canula [12].

Therefore, in patients ready to wean from mechanical ventilation we aimed at comparing both techniques used in clinical practice, namely low PS/PEEP and ATC mode with PEEP [13]. Our hypothesis was that the WOB is greater in ATC than in the low PS/PEEP, and, if it is true, low PS provides support beyond $R_{\mathrm{ET}}$ compensation. Assisted spontaneous breathing is increasingly suspected to damage the lung by promoting excessive trans-pulmonary pressure in the most ventral lung regions [14]. Therefore, our secondary objective was lung ventilation distribution, with the hypothesis of a more ventral distribution with low PS than ATC at same PEEP.

\section{Methods}

The protocol was approved by an Ethics Committee and the National Agency for drug safety in France and registered (NCT02939963 in clinical.trial.gov).

\section{Patients}

Patients were eligible if they met all the following inclusion criteria: (1) age $\geq 18$ years; (2) intubated and mechanically ventilated for acute respiratory failure for at least 24 consecutive hours; (3) able to tolerate PS $10-15 \mathrm{cmH}_{2} \mathrm{O}$ with total respiratory rate $25-35$ breaths/ min and expired tidal volume $6-8 \mathrm{ml} / \mathrm{kg}$ predicted body weight; (4) meeting criteria for SBT (see Additional file 1); (5) under EVITA XL ICU ventilator (Dräger, Germany); (6) agreement to participate from the patient or her/his next of kin. The list of non-inclusion criteria is provided in Additional file 1.

\section{Measurement set-up}

We measured airflow by using a linear pneumotachograph (3700 series, Hans Rudolph, Shawnee, Kansas) and airway pressure (Paw) at the proximal tip of the endotracheal tube. We measured esophageal pressure (Pes) by using a 5Fr specific catheter balloon (CooperSurgical, Inc., Trumbull, CT) descended down to the lower third of esophagus through the nostril. We assessed the proper position of the Pes device [15] and the amount of nonstressed air volume into the esophageal balloon [16] Paw and Pes were connected to pressure transducers (Gabarith PMSET 1DT-XX, Becton-Dickinson, Singapore). Pressure transducers and pneumotachograph were calibrated using a manometer (717 1G, Fluke Biomedical, Everett, Washington) and a precision rotameter (Houdec Glass, Martin Medical, Lyon, France), respectively, at room temperature in each experiment. The set-up had a flow-resistance of $0.79 \mathrm{cmH}_{2} \mathrm{O} / \mathrm{l} / \mathrm{s}$ and a dead space of $20 \mathrm{ml}$. During the experiment the heated-humidifier was working on and the pneumotachograph was not warmed to avoid any risk of endotracheal tube obstruction.

We wrapped the thorax at the 5-6th intercostal space with a 16-electrode electrical impedance tomography (EIT) belt. The belt was connected to an EIT monitor (Pulmovista 500, Dräger, Lubeck, Germany). EIT device measured changes in impedance across the thorax from the measurement of surface potential differences resulting from the application of a low-intensity alternate electrical current generated by pairs of electrodes and rotating around the thorax at a rate of $20 \mathrm{~Hz}$.

\section{Protocol}

This was a crossover study with two treatment arms. Each included patient received both arms in a computergenerated random order. In the ATC arm, the ventilator was set at PS $0 \mathrm{cmH}_{2} \mathrm{O}$, with the shortest rising time, cycling-off $25 \%$ of maximal inspiratory flow, PEEP $4 \mathrm{cmH}_{2} \mathrm{O}$ and ATC on with $100 \%$ inspiratory compensation for the patient's endotracheal tube size. Expiratory ATC was not activated because it was not available in the ventilators used in present study. In the low-PS arm, settings were the same except for $7 \mathrm{cmH}_{2} \mathrm{O}$ PS and ATC off. Each treatment period was applied during $30 \mathrm{~min}$ and was separated by a 30-min period during which baseline ventilator settings were resumed. If the patient did not tolerate SBT (see Additional file 1 for criteria) he/she was switched back to the baseline ventilator settings and qualified as SBT failure.

During the last $2 \mathrm{~min}$ of each treatment period, Paw, Pes and airflow analog signals were continuously recorded at $200 \mathrm{~Hz}$ by using a data logger (Biopac MP150, Biopac, Inc., Goleta, CA). We obtained Paw at $100 \mathrm{~ms}$ (P0.1) by activating a specific function built into the ventilator. Five brief end-expiratory occlusions were automatically generated by the ventilator after manually pushing on a specific button at random during the 2 min of the recording. In the same time, EIT signals were continuously recorded. Paw, Pes, airflow signals were stored for off-line analysis by using Acqknowledge 4.0 version (Biopac, Inc., Goletta, CA). The 
same was done for the EIT signals by using a specific software (EITDataAnalysisTool 6.1, Dräger, Lubeck, Germany).

\section{Data analysis}

Over each recorded breath the measurements were automatically performed under an in-house software developed with the Matlab scripting language. Tidal volume (VT) and respiratory rate were obtained from the flow signal. Inspiration was defined as the flow crossing zero. Resistive $(R)$ and elastic $(E)$ components of WOB done by the patient were obtained from the Campbell diagram and the total WOB was the sum of the $R$ and $E$ components. Muscular pressure (Pmus) was computed as the difference between Pes and VT times chest wall elastance in each breath (Fig. 1). Chest wall elastance was computed as the change in Pes over the breath divided by $4 \%$ vital capacity expected for gender, age and height [17]. The $R$ and $E$ components of breathing power were the product of each WOB component to respiratory rate and expressed as $\mathrm{J} / \mathrm{min}$. The total breathing power was the sum of its $R$ and $E$ components. The pressure-time product of inspiratory muscles (PTPmus) was the area of Pmus over the inspiration in each breath multiplied by the respiratory rate. Intrinsic PEEP was measured as the Pes deflection from the onset of inspiratory effort to the first zero flow. No correction was made for gastric pressure.
P0.1 was measured on the Paw tracings recorded in the data logger at $100 \mathrm{~ms}$ after the first zero flow. The values of the 5 measurements per condition were averaged.

We assessed the functioning of the ventilator in each mode by measuring PEEP, maximal deflection in Paw at the time of inspiratory effort (DPtrig), time delay between onset of inspiratory effort to return to baseline PEEP (DTtrig), maximal inspiratory pressure and maximal inspiratory flow (see Additional file 1).

The EIT signals were processed with the EIT and diffuse optical tomography reconstruction software (EIDORS) [18] licensed under the GNU general public (http://eidors3d.sourceforge.net/) associated with the Matlab scripting language (see Additional file 1).

The pressure drop across the endotracheal tube was evaluated from general mechanical law as described [19]. This pressure drop is a function of the instantaneous flow rate and the endotracheal tube geometry (length and diameter). We measured the pressure generated by the ventilator and we computed the ideal pressure that would only be needed to compensate for RET. The difference between this ideal pressure and effective Paw was computed by summing the instantaneous difference (see Additional file 1 for more details).

\section{Statistical analysis}

The primary end-point was the total breathing power generated by the patient's respiratory muscles and was used to power the study. We set total breathing power

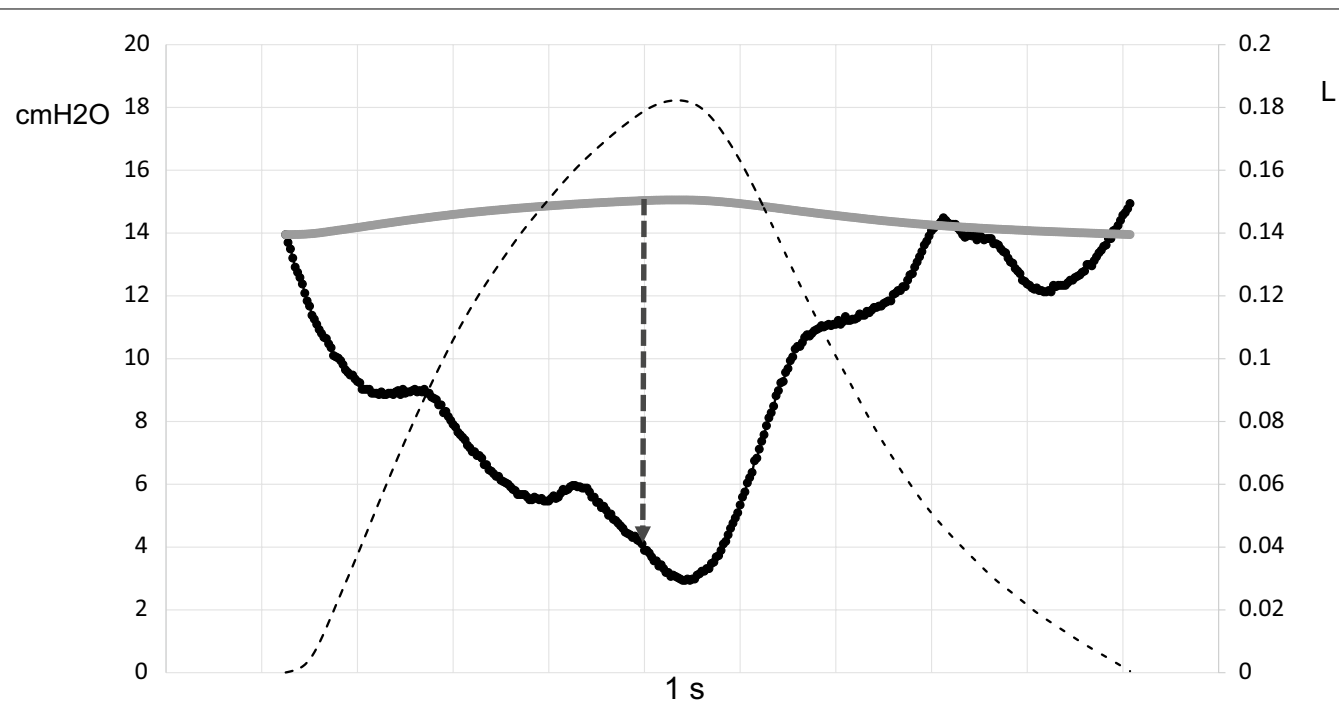

Fig. 1 Method to compute muscular pressure (Pmus) over one breath. Scope mode displays over time the tidal volume (black dashed line), the recorded esophageal pressure (Pes,dyn, black continuous line) and the computed static esophageal pressure (Pes,st gray continuous line) (record from patient \#16 in the automatic tube compensation group). At any time Pmus is the distance (black dashed vertical arrow) pertaining to Pes,dynPes,st. Scale in $\mathrm{cmH}_{2} \mathrm{O}$ in the left $\mathrm{Y}$ axis and in liter (I) in the right $\mathrm{Y}$ axis. Time scale $(1 \mathrm{~s})$ is indicated 
to $10 \mathrm{~J} / \mathrm{min}$ in the low-PS arm reference group [7], and a $4 \mathrm{~J} / \mathrm{min}$ clinically relevant increase in total breathing power with ATC with a $4 \mathrm{~J} / \mathrm{min}$ standard deviation [7]. At first and second risk orders of $5 \%$ and $20 \%$, respectively, 16 patients were needed (Epi-Info software). Assuming a $10 \%$ rate of patients with missing data a total of 20 patients should be enrolled in the study.

The values were expressed as median (1st-3rd quartiles) and compared by non-parametric Wilcoxon signed rank test between the two arms. For the primary endpoint, we furthermore tested the period effect and the treatment-period interaction [20]. If the period has a significant effect the analysis would be adjusted for the period. If the interaction between treatment and period is significant only the first period will be used. Correlation between variables was assessed by using Spearman rank correlation. The statistical analysis was performed by using the $\mathrm{R}$ software 3.5.2 version [21]. $P$ value $<0.05$ was taken as the statistical significant threshold. No correction for multiple comparisons was done.

\section{Results}

\section{Patients sample description}

Twenty patients were included between August 23, 2017 and October 5, 2018 (Fig. 2 and Table 1). All but two were admitted in a medical setting. Time from intubation for acute respiratory failure to study was 7 (4-14) days. The main cause of acute respiratory failure requiring intubation was: community-acquired pneumonia $(n=9)$, aspiration $(n=2)$, fluid overload $(n=3)$, and pulmonary embolism, pleural space infection, acute respiratory distress syndrome of unknown origin, hospital-acquired pneumonia, coma, and chronic obstructive pulmonary disease ( $n=1$ for each). SBT under present investigation was the first for 16 patients, the second for 2 and the third for 2 . All but one succeeded the SBT and were extubated right away thereafter. No adverse event was observed during the study. The day of the study $\mathrm{PaO}_{2} / \mathrm{F}_{\mathrm{I}} \mathrm{O}_{2}$ was 287 (206-362) mmHg, $\mathrm{PaCO}_{2} 38$ (35-41) mmHg, pH 7.45 (7.42-7.49). EIT data were lacking in three patients due to technical problem with the belt functioning. The baseline breathing pattern, breathing power and inspiratory effort at the ventilatory settings shown in Table 1 were the following: VT $0.38(0.31-0.48) \mathrm{l}$, respiratory rate $26(23-31)$ breaths/min, minute ventilation 9.6 (8.4-11.4) $\mathrm{l} / \mathrm{min}$, DTtrig $0.17(0.14-0.20) \mathrm{s}$, DPtrig - 1.9 $(-2.6 ;-1.4) \mathrm{cmH}_{2} \mathrm{O}$, maximal Paw $14(12-16) \mathrm{cmH}_{2} \mathrm{O}$, and total breathing power $8.6(3.3-13.3) \mathrm{J} / \mathrm{min}$ and 3.8 $(1.6-7.2)$ and $4.0(1.5-5.8) \mathrm{J} / \mathrm{min}$ for its resistive and elastic components, respectively.

\section{Effects of SBT mode on breathing pattern and inspiratory effort}

VT, inspiratory and expiratory times were not different between the two periods (Table 2). Respiratory rate was $27(21-33)$ vs. $25(21-28)$ breaths $/ \mathrm{min}(P=0.007)$, and minute ventilation $9.5(7.4-11.7)$ vs. $9.4(8.5-10.1)$ $(P=0.22)$, in ATC and PS periods, respectively.

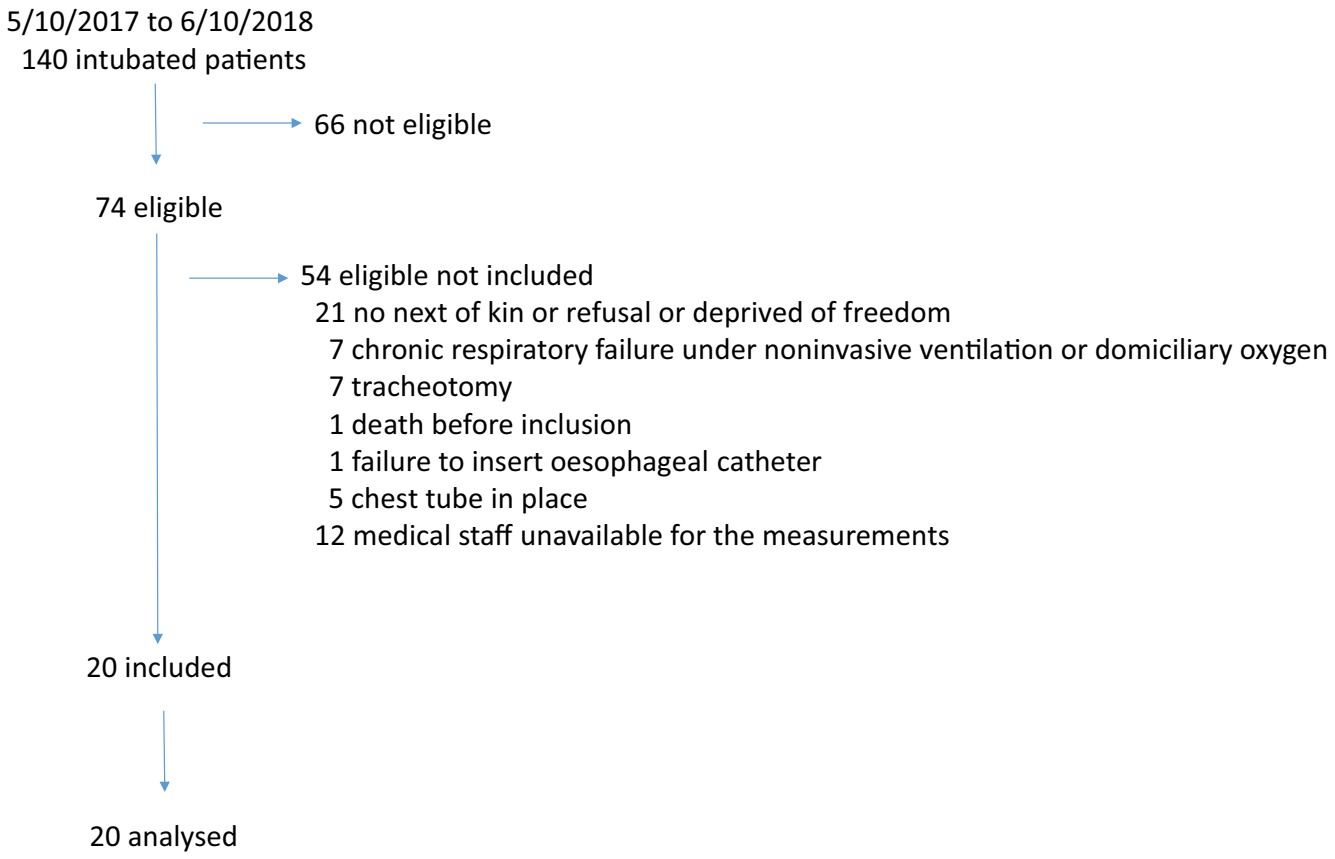

Fig. 2 Flowchart of the patients during the study period 


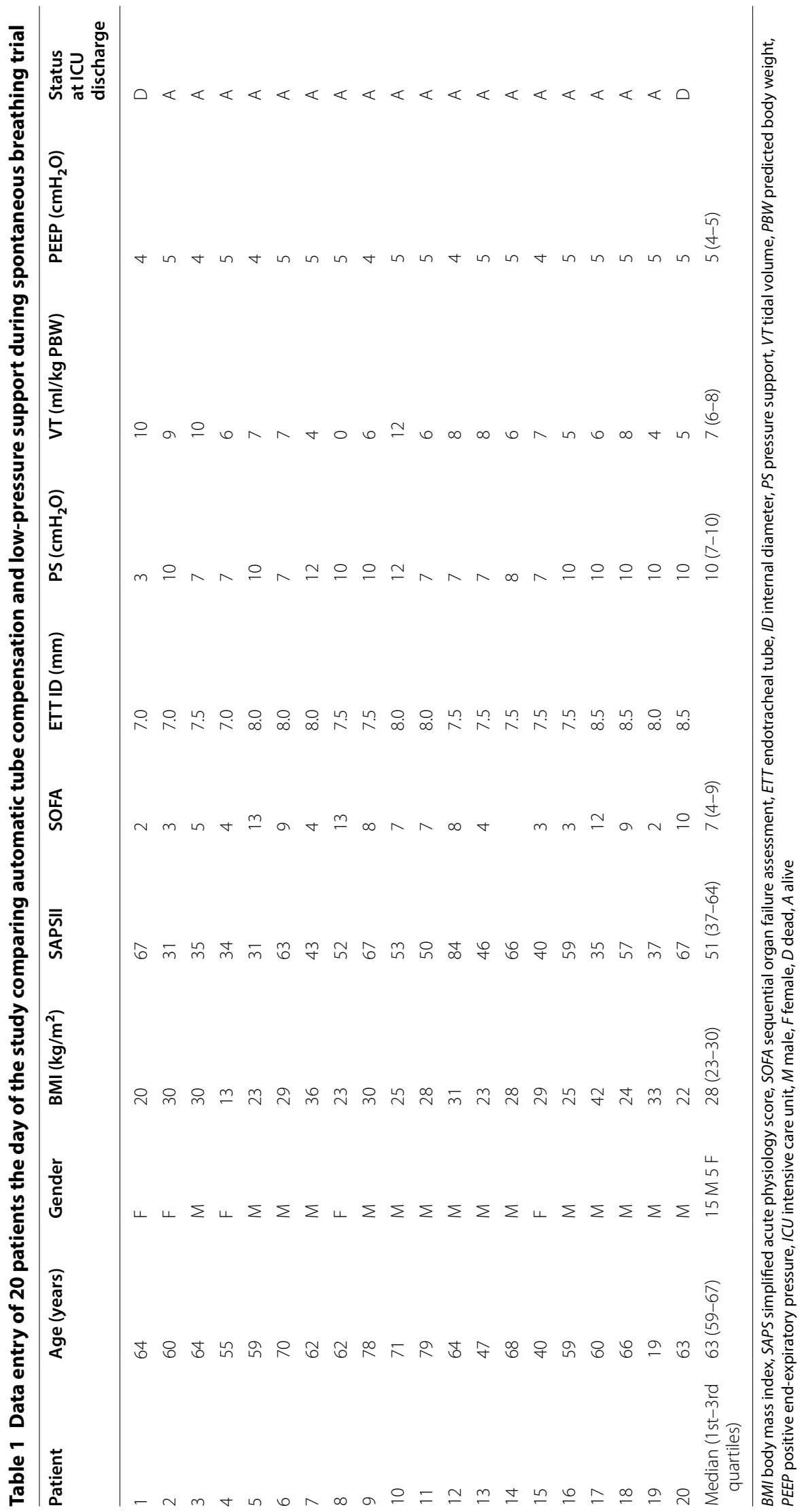


Table 2 Breathing pattern and ventilator functioning in automatic tube compensation and low-pressure support periods during spontaneous breathing trial

\begin{tabular}{|c|c|c|c|}
\hline & ATC & Low PS & $P$ value \\
\hline Tidal volume (I) & $0.35(0.30 ; 0.45)$ & $0.35(0.32 ; 0.50)$ & 0.22 \\
\hline Tidal volume (ml/kg predicted body weight) & $5.3(4.5 ; 6.3)$ & $5.6(4.7 ; 7.7)$ & 0.21 \\
\hline Respiratory rate (breaths/min) & $27(21 ; 33)$ & $25(21 ; 28)$ & 0.007 \\
\hline Minute ventilation (I/min) & $9.5(7.4 ; 11.7)$ & $9.4(8.3 ; 10.4)$ & 0.22 \\
\hline Respiratory rate/tidal volume ratio (breaths/min/l) & $77(52 ; 105)$ & $70(43 ; 88)$ & 0.048 \\
\hline Inspiratory time (s) & $0.95(0.78 ; 1.11)$ & $0.88(0.80 ; 1.05)$ & 0.79 \\
\hline Expiratory time (s) & $1.44(1.10 ; 1.78)$ & $1.72(1.36 ; 1.96)$ & 0.05 \\
\hline Inspiratory/expiratory time ratio (\%) & $0.67(0.54 ; 0.81)$ & $0.55(0.49 ; 0.71)$ & 0.04 \\
\hline $\operatorname{PEEP}\left(\mathrm{cmH}_{2} \mathrm{O}\right)$ & $5(4 ; 5)$ & $5(4-5)$ & 0.60 \\
\hline DPtrig $\left(\mathrm{cmH}_{2} \mathrm{O}\right)$ & $-2(-3 ;-1)$ & $-2(-3 ;-2)$ & 0.60 \\
\hline DTtrig (s) & $0.19(0.12 ; 0.22)$ & $0.15(0.13 ; 0.19)$ & 0.007 \\
\hline Maximal inspiratory pressure $\left(\mathrm{cmH}_{2} \mathrm{O}\right)$ & $8(7 ; 8)$ & $12(12-12)$ & 0.00006 \\
\hline Maximal inspiratory flow (I/s) & $1(1 ; 1)$ & $1(1 ; 1)$ & 0.18 \\
\hline
\end{tabular}

ATC automatic tube compensation, $P S$ pressure support, PEEP positive end-expiratory pressure, DPtrig maximal depression in airway pressure from PEEP during activation of inspiratory trigger, DTtrig time delay between onset of inspiratory effort and return to baseline PEEP before inspiratory valve opening

Values are median (1st; 3rd quartiles)

For the total breathing power generated by the patient's respiratory muscles, the primary end-point of the study, there were no statistically significant effect of neither the period nor the interaction between period and treatment (Table 3). It was significantly higher with ATC [9.7 (5.721.9)] than with low PS [7.2 (4.4-9.6)] $\mathrm{J} / \mathrm{min}(P=0.011)$. The same was true for its resistive $(P=0.035)$ and elastic components $(P=0.0096)$ (Table 3$)$. Between ATC and low PS, PTPmus was 232 (181-349) and 153 (120251) $\mathrm{cmH}_{2} \mathrm{O} \mathrm{s} / \mathrm{min}(P=0.0009)$.

P0.1 was 3.3 (1.6-4.6) $\mathrm{cmH}_{2} \mathrm{O}$ in ATC and 1.9 (1.43.3) $\mathrm{cmH}_{2} \mathrm{O}$ in low-PS group $(P=0.03)$.

There was a significant linear relationship between P0.1 and both total breathing power and PTPmus over all the data points (Fig. 3).

\section{Ventilator support functioning in SBT}

Between ATC and low PS the maximal Paw was, as expected, greater with low PS than with ATC (Table 2).
It is worth mentioning that ATC generated a roughly $3 \mathrm{cmH}_{2} \mathrm{O}$ pressure assistance above PEEP. DTtrig was longer with ATC than with low PS by 40 ms roughly, but this value is likely not clinically relevant even though it reached statistical significance (Table 2).

The pressure generated by the ventilator surpassed the ideal pressure by $25 \%$ in ATC and by $400 \%$ in lowPS mode. That means that the ventilator is further away from the ideal pressure with low PS than with ATC.

\section{Electrical impedance tomography}

At baseline, global inhomogeneity index was 0.56 (0.43$0.67)$, center of ventilation 53 (46-58), anterior-to-posterior tidal impedance distribution $0.7(0.53-1.84)$ and coefficient of variation of ventilation 0.91 (0.81-0.99). EIT indexes were not different between ATC and low-PS periods (Table 4). The Spearman's coefficient of rank correlation values between EIT indexes and breathing power performed over all data points are provided in Table 5.

Table 3 Results of the cross-over design analysis for the breathing power (the primary end-point of the study) in the automatic tube compensation and the low-pressure support periods during spontaneous breathing trial in 20 patients

\begin{tabular}{|c|c|c|c|c|c|}
\hline & ATC & Low PS & Treatment effect & Period effect & $\begin{array}{l}\text { Treatment x period } \\
\text { interaction (carry } \\
\text { over effect) }\end{array}$ \\
\hline Total breathing power (J/min) & $9.7(5.7-21.9)$ & $7.2(4.4-9.6)$ & 0.011 & 0.060 & 0.175 \\
\hline Resistive breathing power (J/min) & $4.8(1.6-9.9)$ & $3.1(1.9-4.6)$ & 0.035 & 0.086 & 0.116 \\
\hline Elastic breathing power (J/min) & $5.0(3.6-7.7)$ & $3.5(2.4-5.2)$ & 0.0096 & 0.081 & 0.238 \\
\hline
\end{tabular}

Values are median (1st-3rd quartiles)

ATC automatic tube compensation, PS pressure support, $\mathrm{J} / \mathrm{min}$ joules per minute 


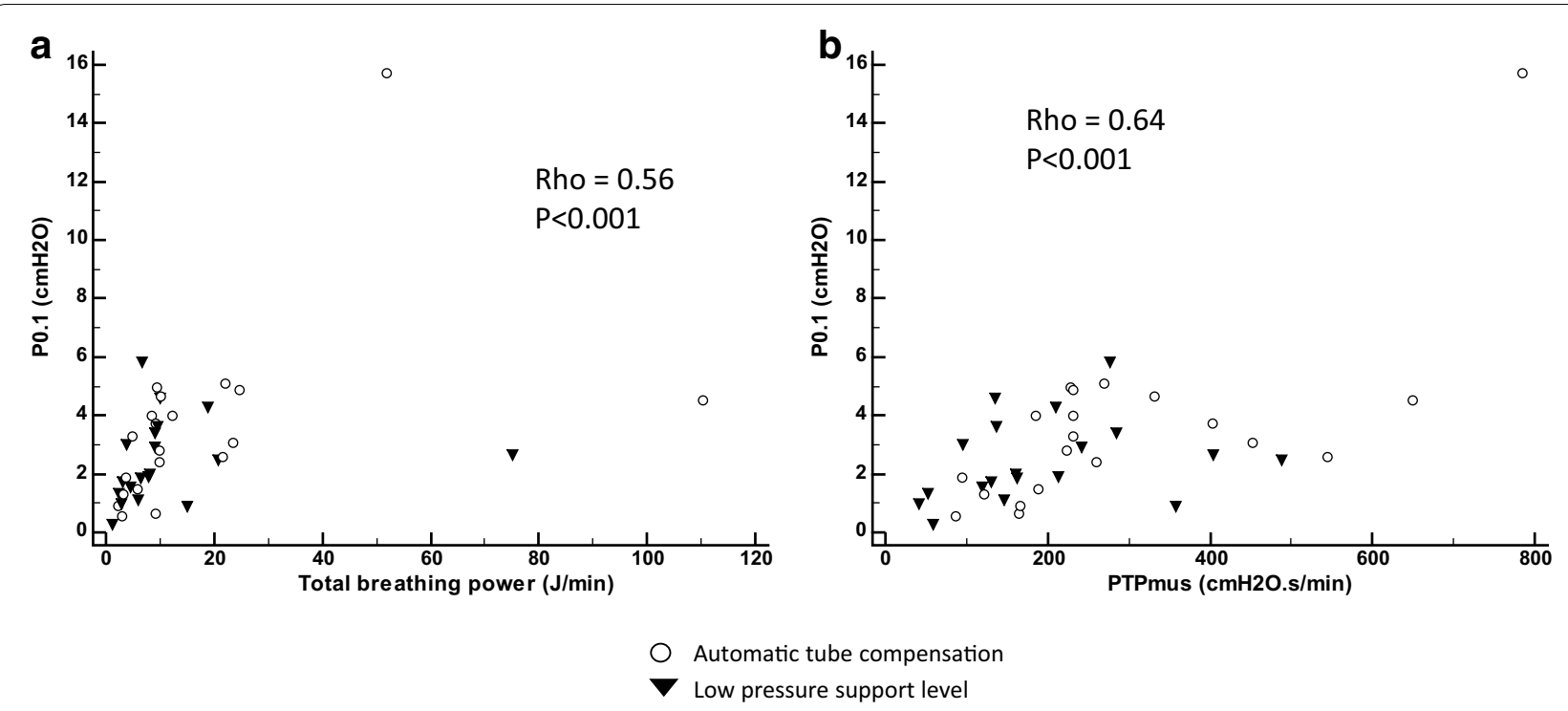

Fig. 3 Relationships between airway pressure at $100 \mathrm{~ms}$ after occlusion (P0.1) and breathing power (a) and pressure time product performed by the respiratory muscles (PTPmus) (b). Rho Spearman correlations are shown for all over the data points. Open circles for automatic tube compensation group and black triangles for low-pressure support group

Table 4 Electrical impedance tomography indexes in automatic tube compensation and low-pressure support periods during spontaneous breathing trial in 17 patients

\begin{tabular}{llll}
\hline & ATC & Low PS & P value \\
\hline Anterior-to-posterior impedance ratio & $0.69(0.58-1.59)$ & $0.86(0.49-1.61)$ & 0.55 \\
Center of ventilation & $54.8(46.3-58.1)$ & $53.7(46.0-60.2)$ & 0.82 \\
Global inhomogeneity index & $0.62(0.47-0.80)$ & $0.65(0.50-0.75)$ & 0.35 \\
Coefficient of variation & $0.95(0.81-1.82)$ & $0.96(0.77-1.39)$ & 0.68 \\
\hline
\end{tabular}

Values are median (1st-3rd quartiles)

ATC automatic tube compensation, PS pressure support

Table 5 Spearman's coefficient of rank correlation between electrical impedance tomography indexes and breathing power performed over all the data points

\begin{tabular}{|c|c|c|c|c|}
\hline \multirow[t]{2}{*}{ Breathing power } & \multicolumn{4}{|c|}{ Electrical impedance tomography indexes } \\
\hline & Anterior-to-posterior ratio & Center of ventilation & Coefficient of variation & $\begin{array}{l}\text { Global } \\
\text { inhomogeneity } \\
\text { index }\end{array}$ \\
\hline Elastic & $-0.38^{*}$ & $0.39^{*}$ & -0.18 & $0.34^{*}$ \\
\hline Resistive & $-0.39^{*}$ & $0.41^{*}$ & -0.18 & $0.43^{*}$ \\
\hline Total & $-0.36^{*}$ & $0.37^{*}$ & -0.16 & $0.41^{*}$ \\
\hline
\end{tabular}

${ }^{*} P<0.05$

\section{Discussion}

The main finding of present study was that breathing power was significantly higher with ATC than with low PS and without ATC at same PEEP. This result confirms our working hypothesis that low PS provides respiratory assistance above $R_{\mathrm{ET}}$.

\section{Work of breathing}

Similar result was reported by Kuhlen et al. [22], who compared PS $7 \mathrm{cmH}_{2} \mathrm{O}$ and PEEP $7 \mathrm{cmH}_{2} \mathrm{O}$, ATC and PEEP $8 \mathrm{cmH}_{2} \mathrm{O}$ and T-piece trial and PEEP $0 \mathrm{cmH}_{2} \mathrm{O}$ in 12 patients undergoing SBT. It is worth mentioning that the investigators used a previous ventilator (Evita 4 
vs. Evita XL in present study), endotracheal tubes much larger than in present study, the amount of $R_{\mathrm{ET}}$ compensation was not indicated, and distribution of ventilation not assessed. Therefore, present study extended previous results [22]. Interestingly, the values of PTPmus and P0.1 were very close between each study in both periods. Also remarkable is that the same respiratory assistance level, amounting to $3 \mathrm{cmH}_{2} \mathrm{O}$, was observed with the ATC mode in both studies. The previous generation of Evita ventilators is very close to the next one in the amount of support generated in ATC mode. Taking these two studies together, it can be concluded that low PS of $7 \mathrm{cmH}_{2} \mathrm{O}$ does not only compensate for $R_{\mathrm{ET}}$, but also provides a real respiratory assistance and unloads the patient as compared to a spontaneous breathing mode that compensates only for $R_{\mathrm{ET}}$. Whether or not other brands of ventilators would result in same respiratory breathing assistance in ATC remains to be investigated.

Cabello et al. compared in 14 difficult-to-wean patients in a cross-over design PS $7 \mathrm{cmH}_{2} \mathrm{O}$ PEEP 5 or $0 \mathrm{cmH}_{2} \mathrm{O}$ and T-piece for $60 \mathrm{~min}$ each [7]. From the former to the latter SBT method WOB and PTPmus increased progressively. Of notice breathing power was of same magnitude in ATC group of present study and low-PS PEEP $0 \mathrm{cmH}_{2} \mathrm{O}$ in [7].

We found a significant correlation between P0.1 and breathing power. Therefore, $\mathrm{P} 0.1$ could be a tool to titrate the level of PS during SBT.

\section{Regional distribution of ventilation}

Assessing distribution of ventilation at the time of weaning has been poorly investigated. Such assessment is, however, important because assisted spontaneous breathing may promote overdistension in either ventral or dorsal lung regions [23, 24]. Therefore, lung protection should be a target as important at the time of weaning as in earlier stage of mechanical ventilation [25]. On the other hand, loss of aeration may occur during SBT and has been shown to predict weaning outcome when assessed by lung ultrasound [26].

We used EIT, which is a radiation-free, non-invasive method to determine regional ventilation distribution [27]. It has a favorable comparison with gold standard technique to measure lung ventilation quantitatively [28]. In present study, the EIT indexes were similar between each ventilator mode. There is no previous study for ATC and low PS on EIT indexes during SBT to compare with. Mauri et al. compared two PS levels at same PEEP of $7 \mathrm{cmH}_{2} \mathrm{O}$ in 10 ARDS patients [29]. Dorsal distribution of lung ventilation increased and distribution of ventilation was more homogeneous in low $\left(3 \mathrm{cmH}_{2} \mathrm{O}\right)$ as compared to high $\left(12 \mathrm{cmH}_{2} \mathrm{O}\right)$ PS levels [30]. In present study the difference in PS level between low PS and ATC averaged $4 \mathrm{cmH}_{2} \mathrm{O}$ (Table 3) and may be not sufficient to induce changes in ventilation distribution. Moreover, our patients were ready to wean, and we can expect that their potential lung inhomogeneity is less marked than in ARDS patients. However, present EIT findings suggest that ATC would not increase lung ventilation heterogeneity as compared to low PS and low PEEP that is likely to maintain lung ventilation homogeneous. We found that anterior-to-posterior lung ventilation distribution, center of ventilation and global inhomogeneity EIT indexes correlated with breathing power, even though the correlation was weak. These findings would suggest that heterogeneity of ventilation would increase with breathing power setting the risk of lung injury [31]. Hsu et al. compared assisted volume-controlled mechanical ventilation to ATC $100 \%$ PEEP $5 \mathrm{cmH}_{2} \mathrm{O}$ in 16 patients under invasive mechanical ventilation for 40 days [32]. The distribution of ventilation was higher in dorsal than in ventral regions with ATC. Zhao et al. found that greater weaning success in patients with better redistribution towards the dorsal lung regions [33]. Bickenbach et al. found that EIT indexes, like impedance ratio between dorsal and ventral lung regions, intra-tidal variation of impedance, global inhomogeneity index, regional ventilation delay, end-expiratory lung impedance, may predict the success or failure of SBT [34]. We found meaningless in present study to compare the single patient who failed with the 19 who succeeded SBT.

\section{Limitations and strengths}

Present study was limited by the lack of a T-piece without ATC condition and of WOB measurement after extubation. This choice was made because our study was hypothesis-driven. We did not measure gastric pressure to take into account expiratory muscles contraction. However, we did not observe any significant Pes change during expiration. Our study has strengths as it is the first assessing the distribution of lung ventilation in ATC as compared to low PS during SBT. The sample size was a priori computed.

\section{Clinical implications}

Present study was crossed-over and not designed to determine whether one mode would be better than the other to predict SBT failure, or to be used during the whole weaning process. Cohen et al. [35] performed a randomized controlled trial in ready-to-wean patients. They compared ATC $100 \%$ to $7 \mathrm{cmH}_{2} \mathrm{O}$ PS both at same PEEP of $5 \mathrm{cmH}_{2} \mathrm{O}$ for $1 \mathrm{~h}$ to predict extubation outcome. The rate of successful extubation was the same between the two periods. This study was close to the present one regarding SBT strategies. Of notice COPD patients accounted for 8 and $11 \%$ in the ATC and low-PS periods, 
respectively. Applying our results on breathing power to the study by Cohen et al. [35] would suggest that even low PS can reduce significantly WOB it would not be better than ATC for SBT outcome. A recent large randomized controlled trial compared 578 patients who received a 2-h T-piece trial to 575 patients who received low PS $\left(8 \mathrm{cmH}_{2} \mathrm{O}\right)$ for 30 min without PEEP in each [5]. The primary outcome was the rate of successful extubation. It was $82.3 \%$ in the low-PS group and $74 \%$ in the T-piece group $(P=0.001)$. Whereas T-piece trial could be the best test to replicate the physiological conditions after extubation, PS trial seems to be the best test to hasten extubation without an increased risk of reintubation. ATC would deserve a trial during weaning because it shares both advantages of low PS by providing some ventilatory assistance and of SBT in replicating physiological conditions increased. We can also note that poor trigger performance (DTtrig $>150 \mathrm{~ms}$ ) of the ventilator would make it more difficult to see difference between low PS, ATC or SBT. It is worth mentioning that SBT success is not the same as weaning success, which is commonly assessed $48 \mathrm{~h}$ after extubation [1]. Furthermore, recent data indicate that clinicians do not offer a SBT in almost $50 \%$ of patients and that successful SBT is not always followed by extubation [36]. The data of the large prospective epidemiological study (Wean safe) are coming up soon and would tell us more about the practice of weaning all over the world (NCT03255109).

\section{Conclusions}

We found that ATC was associated with higher breathing power than low PS during SBT without altering the distribution of lung ventilation.

\section{Supplementary information}

Supplementary information accompanies this paper at https://doi. org/10.1186/s13613-019-0611-y.

Additional file 1. Methods.

\begin{abstract}
Abbreviations
ATC: automatic tube compensation; DPtrig: maximal airway pressure required to open the inspiratory valve; DTtrig: time required to generate DPtrig; $E$ : elastance; EIT: electrical impedance tomography; ICU: intensive care unit; P0.1: airway pressure $100 \mathrm{~ms}$ after onset of inspiratory effort; Paw: airway pressure; PEEP: positive end-expiratory pressure; Pes: esophageal pressure; Pmus: muscular pressure; PS: pressure support; PTPmus: pressure time product of respiratory muscles; $R$ : resistance; $R_{\mathrm{ET}}$ : resistance of endotracheal tube; SBT: spontaneous breathing trial; VT: tidal volume; WOB: work of breathing.
\end{abstract}

\section{Acknowledgements}

Not applicable.

\section{Authors' contributions}

CG—substantial contributions to the conception or design of the work; acquisition, analysis, interpretation of data and drafting the work;
NT-interpretation of data for the work; NT, MM, LB, NC, HY, LA, LH, BL-revising it critically for important intellectual content; MM, LB, NC, HY-acquisition of data; $\mathrm{LA}$, LH-interpretation of data; $\mathrm{BL}$-analysis, interpretation and acquisition of data. CG, NT, MM, LB, NC, HY, LA, LH, BL-agreement to be accountable for all aspects of the work in ensuring that questions related to the accuracy or integrity of any part of the work are appropriately investigated and resolved. All authors read and approved the final manuscript.

\section{Funding}

None. Electrical impedance tomography device (Pulmovista) was provided by Draeger France.

\section{Availability of data and materials}

All data generated or analyzed during this study are included in this published article [and its additional information files].

\section{Ethics approval and consent to participate}

The study was approved by an ethical committee on October 18, 2016 and by the National agency for drug safety on September 19, 2016, and registered on clinical trials website as NCT02939963. Before inclusion into the study every patient or next of kin gave a signed consent to participate after reading an information notice.

\section{Consent for publication}

Not applicable.

\section{Competing interests}

The authors declare that they have no competing interests.

\section{Author details}

${ }^{1}$ Médecine-Intensive Réanimation, Hopital Edouard Herriot, CHU de Lyon, Lyon, France. ${ }^{2}$ Université de Lyon, Lyon, France. ${ }^{3}$ INSERM 955, Créteil, France. ${ }^{4}$ CNRS ERL 7000, Créteil, France. ${ }^{5}$ Médecine-Intensive Réanimation, CHU de Grenoble-Alpes, La Tronche, France. ${ }^{6}$ Université de Grenoble-Alpes, Saint-Martin-d'Hères, France. ${ }^{7}$ INSERM 1042, Grenoble, France. ${ }^{8}$ Médecine-Intensive Réanimation, Groupement Hospitalier Nord, CHU de Lyon, Lyon, France.

${ }^{9}$ Department of Intensive Care, University of Amsterdam, Amsterdam, The Netherlands.

Received: 23 August 2019 Accepted: 27 November 2019

Published online: 13 December 2019

References

1. Boles JM, Bion J, Connors A, et al. Weaning from mechanical ventilation. Eur Respir J. 2007;29(5):1033-56.

2. Esteban A, Alia I, Gordo F, et al. Extubation outcome after spontaneous breathing trials with T-tube or pressure support ventilation. The Spanish Lung Failure Collaborative Group. Am J Respir Crit Care Med. 1997;156(2 Pt 1):459-65.

3. Burns KEA, Soliman I, Adhikari NKJ, et al. Trials directly comparing alternative spontaneous breathing trial techniques: a systematic review and meta-analysis. Crit Care. 2017;21(1):127.

4. Schmidt GA, Girard TD, Kress JP, et al. Official Executive Summary of an American Thoracic Society/American College of Chest Physicians Clinical Practice Guideline: liberation from Mechanical Ventilation in Critically III Adults. Am J Respir Crit Care Med. 2017;195(1):115-9.

5. Subira C, Hernandez G, Vazquez A, et al. Effect of pressure support vs T-piece ventilation strategies during spontaneous breathing trials on successful extubation among patients receiving mechanical ventilation: a randomized clinical trial. JAMA. 2019;321(22):2175-82.

6. Brochard L, Rua F, Lorino H, Lemaire F, Harf A. Inspiratory pressure support compensates for the additional work of breathing caused by the endotracheal tube. Anesthesiology. 1991;75(5):739-45.

7. Cabello B, Thille AW, Roche-Campo F, Brochard L, Gomez FJ, Mancebo J. Physiological comparison of three spontaneous breathing trials in difficult-to-wean patients. Intensive Care Med. 2010;36(7):1171-9.

8. Ishaaya AM, Nathan SD, Belman MJ. Work of breathing after extubation. Chest. 1995;107(1):204-9. 
9. Nathan SD, Ishaaya AM, Koerner SK, Belman MJ. Prediction of minimal pressure support during weaning from mechanical ventilation. Chest. 1993;103(4):1215-9.

10. Sklar MC, Burns K, Rittayamai N, et al. Effort to breathe with various spontaneous breathing trial techniques. A physiological meta-analysis. Am J Respir Crit Care Med. 2016;195:1477-85.

11. Kacmarek RM. Ventilatory adjuncts. Respir Care. 2002;47(3):319-30 (discussion 330-3).

12. Guttmann J, Haberthur C, Mols G, Lichtwarck-Aschoff M. Automatic tube compensation (ATC). Minerva Anestesiol. 2002;68(5):369-77.

13. Richard $C$, Beydon $L$, Cantagrel $S$, et al. Société de Réanimation de Langue Française, XXI e Conférence de Consensus en Réanimation et en Médecine d'urgence. Sevrage de la ventilation mécanique. Réanimation. 2001;10:699-715.

14. Brochard L, Slutsky A, Pesenti A. Mechanical ventilation to minimize progression of lung injury in acute respiratory failure. Am J Respir Crit Care Med. 2017;195(4):438-42.

15. Baydur A, Behrakis PK, Zin WA, Jaeger M, Milic-Emili J. A simple method for assessing the validity of the esophageal balloon technique. Am Rev Respir Dis. 1982;126(5):788-91.

16. Mojoli F, lotti GA, Torriglia F, et al. In vivo calibration of esophageal pressure in the mechanically ventilated patient makes measurements reliable. Crit Care. 2016;20:98.

17. Agostoni E, Mead J. Statics of the respiratory system. In: Society AP, editor. Handbook of physiology, vol. 1. Washington: DC; 1964. p. 387-409.

18. Adler A, Lionheart WR. Uses and abuses of EIDORS: an extensible software base for EIT. Physiol Meas. 2006;27(5):S25-42

19. Lofaso F, Louis B, Brochard L, Harf A, Isabey D. Use of the Blasius resistance formula to estimate the effective diameter of endotracheal tubes. Am Rev Respir Dis. 1992;146(4):974-9.

20. Pocock SJ. Clinical Trials: a practical approach. Hoboken: Wiley; 1984

21. R: a language and environment for statistical computing. program]. $R$ Foundation for Statistical Computing; 2013.

22. Kuhlen R, Max M, Dembinski R, Terbeck S, Jurgens E, Rossaint R. Breathing pattern and workload during automatic tube compensation, pressure support and T-piece trials in weaning patients. Eur J Anaesthesiol. 2003;20(1):10-6.

23. Yoshida T, Torsani V, Gomes S, et al. Spontaneous effort causes occult pendelluft during mechanical ventilation. Am J Respir Crit Care Med. 2013;188(12):1420-7.

24. Yoshida T, Uchiyama A, Matsuura N, Mashimo T, Fujino Y. The comparison of spontaneous breathing and muscle paralysis in two different severities of experimental lung injury. Crit Care Med. 2013;41(2):536-45.

25. Brochard L, Slutsky A, Pesenti A. Mechanical ventilation to minimize progression of lung injury in acute respiratory failure. Am J Respir Crit Care Med. 2016;195:438-42.
26. Soummer A, Perbet $\mathrm{S}$, Brisson $\mathrm{H}$, et al. Ultrasound assessment of lung aeration loss during a successful weaning trial predicts postextubation distress*. Crit Care Med. 2012;40(7):2064-72.

27. Frerichs I, Amato MB, van Kaam AH, et al. Chest electrical impedance tomography examination, data analysis, terminology, clinical use and recommendations: consensus statement of the TRanslational EIT developmeNt stuDy group. Thorax. 2017;72(1):83-93.

28. Richard JC, Pouzot C, Gros A, et al. Electrical impedance tomography compared to positron emission tomography for the measurement of regional lung ventilation: an experimental study. Crit Care. 2009;13(3):R82.

29. Mauri T, Bellani G, Confalonieri A, et al. Topographic distribution of tidal ventilation in acute respiratory distress syndrome: effects of positive end-expiratory pressure and pressure support. Crit Care Med. 2013;41(7):1664-73.

30. Amico AP, Terlizzi A, Damiani S, Ranieri M, Megna M, Fiore P. Immunopharmacology of the main herbal supplements: a review. Endocr Metab Immune Disord Drug Targets. 2013;13(4):283-8.

31. Gattinoni L, Tonetti $T$, Cressoni $M$, et al. Ventilator-related causes of lung injury: the mechanical power. Intensive Care Med. 2016;42(10):1567-75.

32. Hsu YL, Tien AJ, Chang MY, et al. Regional ventilation redistribution measured by electrical impedance tomography during spontaneous breathing trial with automatic tube compensation. Physiol Meas. 2017;38(6):1193-203.

33. Zhao Z, Peng SY, Chang MY, et al. Spontaneous breathing trials after prolonged mechanical ventilation monitored by electrical impedance tomography: an observational study. Acta Anaesthesiol Scand. 2017;61(9):1166-75.

34. Bickenbach J, Czaplik M, Polier M, Marx G, Marx N, Dreher M. Electrical impedance tomography for predicting failure of spontaneous breathing trials in patients with prolonged weaning. Crit Care. 2017;21(1):177.

35. Cohen J, Shapiro M, Grozovski E, Fox B, Lev S, Singer P. Prediction of extubation outcome: a randomised, controlled trial with automatic tube compensation vs. pressure support ventilation. Crit Care. 2009;13(1):21.

36. Beduneau G, Pham T, Schortgen F, et al. Epidemiology of weaning outcome according to a new definition. The WIND Study. Am J Respir Crit Care Med. 2017;195(6):772-83.

\section{Publisher's Note}

Springer Nature remains neutral with regard to jurisdictional claims in published maps and institutional affiliations.

\section{Submit your manuscript to a SpringerOpen ${ }^{\circ}$ journal and benefit from:}

- Convenient online submission

- Rigorous peer review

- Open access: articles freely available online

- High visibility within the field

Retaining the copyright to your article

Submit your next manuscript at springeropen.com 